clinically suspected thrombosis. One week after cessation of heparin treatment she again developed symptoms and thermography clearly showed a thrombosis. Phlebography below the inguinal ligament showed an occluding thrombus in the femoral vein just above the knee joint. She was followed thermographically once a week. Heparin treatment was given until one week before a normal delivery. Thermography became negative after about 10 weeks' treatment, suggesting an inactive thrombus. Phlebography one week post partum showed complete resolution of the thrombus. The other patient, aged 26 , had a clinically suspected deep venous thrombosis in the 10th week of her pregnancy. Ascending phlebography showed normal deep veins in the calf and distal part of the thigh, but strain-gauge plethysmography showed a proximally located thrombosis. The record showed a two-stage venous emptying in the left leg, with a first phase of rapid emptying from the calf and then a slow one through the proximal veins. Intravenous and then subcutaneous heparin therapy was instituted but there was a spontaneous abortion in the 13th week of pregnancy.

Doppler measurement should also be mentioned in this context, although we have but little personal experience of this procedure in the diagnosis of deep venous thrombosis.

A BERGQVIST

D BERGQVIST

T HALLBÖÖK

Departments of Surgery and of
Gynaecology and Obstetrics, Kärnsjukhuset,
Skövde, Sweden

1 Ramsay, D M, Obstetrics and Gynecology, 1975, 45,

${ }^{2}$ Cooke, E D, and Pilcher, M F, British fournal of Surgery, 1974, 61, 971 .

Bergqvist, D, et al, British Medical fournal, 1975, 4,

684.
Bergquist, E, et al, Uppsala fournal of Medical Sciences, $1973,78,191$.
Hallböok,

fournal of Laboratory and Clinical Investigation fournal of Let
$1970,25,413$.

\section{Women in medicine}

SIR,-I was very interested to read the account of the second session of the BMF Conference on Medical Manpower which dealt with the problems of women in medicine (10 January, p 78). I would agree with the chairman's opening remark that there has been too little serious thought given to the difficulties faced by women doctors, although there have been pockets of activity in this sphere for many years. The Medical Women's Federation has maintained a representative structure throughout the UK since 1917 which has attempted (with some success I believe) to identify these problems and initiate solutions in the places where these might be found. The Board of Science of the BMA also had an active subcommittee in this sphere some years ago which made some progress, and we have been able to pursue some of the practical anomalies and difficulties through the main committees of the Association, which usually consider sympathetically the matters in this field when these are placed before them (frequently by their women members) and lend strong support when this is reasonable.

The difficulties, we have found, have varied in character over the years from the original "struggle" to obtain adequate places in medical schools and hospital posts, through the difficulties of different pay levels for men and women doctors and the dismissal of female medical officers on marriage, to the presentday problems of recognition and provision of part-time training in hospital and general practice and the scarcity and high cost (with no tax relief) of replacements in the home to care for children or elderly dependent relatives that face doctors who cannot devote themselves full-time to medical work.

I was, perhaps, even more interested in the correspondence (24 January, p 225) stimulated by the conference report. Dr Frada Eskin raises the interesting issue of the selection of medical students and, although it would be nice to feel one could forecast the future attitudes of female applicants in relation to their development and attitudes to interpersonal relationships as yet unknown, surely many doctors feel that better methods of assessmen of motivation should be possible. She links this with the need for a counselling service early in the medical course. We have been encouraged to see the gradual increase in the appointment by area health authorities and boards of advisers to women doctors (sometimes linked with the network of voluntary liaison officers established some years ago by the Medical Women's Federation) who will it is hoped, gradually extend their sphere into the undergraduate population as well as the graduate.

Drs C F Scurr and Charlotte F Paterson both write of the need for career choice and the need for guidance and advice in planning and trainingpoints with which I heartily agree-and here again the advisers and the regional committees for postgraduate medical education have a great part to play and are, in my experience, becoming much more aware of the needs and possible provisions to meet them.

Dr Paterson goes on to make a plea for help in the area of the scarcity and current high cost of domestic replacement and Dr Nimi Ettlinger adds her voice too and asks for corporate action to promote such facilities. The Medical Women's Federation has in the past constituted such a group that has felt the need to devote time and energy (and funds) to an attempt to assess attitudes of women doctors throughout the country and identify situations where action seems necessary to try to promote solutions to problems they see arising. In spite of the increasing number of women doctors and the undoubted growing recognition of their career difficulties I believe a group of this kind will be necessary for some time to come. Not, I should like to suggest, as Dr Paterson says to "fight" but to undertake identification of anomalies and problems and to enlist the aid of their medical colleagues (usually given willingly in my experience) and the administrators in their alleviation.

JOAN K SUTHERLAND

Edinburgh President,

SIR,-How sad to hear all those lady doctors advocating maternity leave, babyminders, crèches, and project sessions in school in the holidays for their children. At a time when it is quite clear that maternal deprivation can have serious and lasting consequences it is strange that the very mothers who ought to be aware of this are putting their own careers first and their children's needs second. Should our offspring join the ranks of the deprived because their mothers are doctors?

Part-time work and career structures should be far more acceptable in as many specialties as is practical-for example, from one or two sessions per week when the children are babies or toddlers up to full time or almost full time when they are ready to leave the nest. I myself moonlight out to do family planning and cytology clinics when our three small children are in bed-not wholly by choice but because tiny daytime jobs are impossible to come by. Unlike Dr Tom Arie (10 January, p 79) I do not find these soul-destroying-after all, every job is what one makes of it.

Dullatur,

Hazel O C Campbell

East Dunbartonshire

SIR,-I read with interest the discussion on women in medicine (10 January, p 78) but noticed one omission-no mention of the possibilities of part-time work in academic medicine and research. During the past 18 years three married women with children have worked part time for a PhD in the faculty of medicine at the Queen's University of Belfast and have been successful. Academic terms frequently correspond with school terms, and hours can be made flexible.

If Dr Mary White is happy as a surgeon's daily help there is no reason why a suitable female should not succeed as the professor's handmaid.

Belfast

Margaret Elmes

\section{Women in psychiatry}

SIR,-I should be grateful if you would allow me through your correspondence columns to inform readers of the existence of the recently formed Working Party on Women in Psychiatry. This small group is seeking information and contributions from all doctors with an interest in women working in psychiatry. A high proportion of psychiatrists are women, but their distribution between the training and career grades shows that a relatively small proportion are appointed to consultant posts. The working party will be considering employment opportunities, with particular reference to types of post available and part-time employment, and the availability of training. We shall be looking at the experience required for specialist accreditation at higher professional training level. We particularly wish to look at the experience of women training in personal posts set up under $H M(69) 6$ and hope to set up a register to monitor the eventual outcome.

Many women working in psychiatry are employed as clinical assistants for up to nine sessions weekly and have considerable experience in the specialty. They are not eligible for the hospital practitioner grade as this is restricted to principals in general practice. We would welcome the views of these doctors and others on an acceptable service grade contract.

The working party hopes to prepare a report for the Education Committee of the Royal College of Psychiatrists by the end of 1976 We should welcome contributions of personal experience and opinions relevant to our task.

\section{Pamela Ashurst} Chairman, Working Party on Women in Psychiatry,

17 Belgrave Square,
London SW 1 X 8PG

\section{Not so double-blind?}

SIR,-We are concerned at the rather loose way the term "double-blind" is often used in reports of clinical trials.

Surely, to justify the term double-blind the 